\title{
Teoria e práticas urbanas: estética, conhecimento e o traçado urbano da cidade de Erechim/RS.
}

Urban theory and practices: aesthetics, knowledge and the urban layout of the city of Erechim / RS.

Camila Nardino*, Dirceu Piccinato Junior**

*Arquiteta e Urbanista, Especialista em Arquitetura Comercial, Mestranda do Programa de Pós-Graduação Stricto Sensu em Arquitetura e Urbanismo da Faculdade Meridional - IMED, camila.nardino@yahoo.com.br

**Doutor em Urbanismo e Docente do Programa de Pós-Graduação Stricto Sensu em Arquitetura e Urbanismo da Faculdade Meridional - IMED, dirceu.piccinato@imed.edu.br

\section{Palavras-chave:}

Morfologia urbana.

Plano urbano.

Parcelamento do solo.

\section{Keywords:}

Urban morphology.

Urban plan.

Installment of the soil.

\section{Resumo}

Erechim foi desenvolvida a partir de um plano urbano idealizado pelo Engenheiro Civil Carlos Torres Gonçalves. A forte presença de formas geométricas retilíneas indicava uma similaridade para com outros desenhos urbanos, como por exemplo, as cidades de Paris (França), Belo Horizonte (Brasil). Para tanto, o presente artigo tem como objetivo desenvolver uma análise morfológica e ideológica sobre a cidade de Erechim. Os procedimentos metodológicos se estruturam em uma pesquisa exploratória, de natureza qualitativa. Foi-se realizado um levantamento histórico, com análises dos processos de formação da cidade e de seu histórico, com análises dos processos de formação da cidade e de seu
traçado urbano. Tal conjuntura permitiu estabelecer o recorte temporal entre o ano de formação da Colônia de Erechim, 1904, até a implantação do traçado urbano em 1914. Algumas particularidades são observadas nesse processo de conformação da cidade, como os eixos norte e sul delineados pelas vias que priorizam a circulação. Notou-se que, ao mesmo tempo em que há um discurso revelando que o traçado urbano de Erechim se inspirou em Paris, há também, por outro lado, a represende Ecrechim se inspirou em Paris, ha também, por outro lado, a representação da ideia de que a cidade se configurou segundo os preceitos do saber erudito da época, assim como, também seguiu algumas

\section{Abstract}

Erechim was developed from an urban plan idealized by Civil Engineer Carlos Torres Gonçalves. The strong presence of rectilinear geometric shapes indicated a similarity to other urban designs, such as the cities of Paris (France), Belo Horizonte (Brazil). To this end, this article aims to develop a morphological and ideological analysis of the city of Erechim. The methodological procedures are structured in exploratory, qualitative research. A historical survey was carried out, with analyzes of the processes of formation of the city and its urban layout. This conjuncture allowed the establishment of the time frame between the year of formation of the Colony of Erechim, 1904, until the implementation of the urban layout in 1914. Some particularities are observed in this process of conformation of the city, such as the north and south axes outlined by the roads that prioritize circulation. It was noted that, while there is a discourse revealing that the urban layout of Erechim was inspired by Paris, there is also, on the other hand, the representation of the idea that the city was configured according to the precepts of erudite knowledge the time, as well as, also for as well as, also followed some guidelines established at the time for the subdivision of urban land. 


\section{Introdução}

A cidade de Erechim é localizada ao norte do estado do Rio Grande do Sul. Segundo o censo do IBGE do ano de 2010, possui uma população de 96.087 habitantes, sendo classificada na $19^{\circ}$ colocação entre as cidades mais populosas do estado (IBGE, 2019).

A cidade de Erechim foi criada e desenvolvida a partir de um traçado urbano estabelecido por quadras fortemente delineadas pelas formas geométricas de quadrados ou de retângulos. Essas quadras formadas por linhas retas que se replicam formam o tecido urbano da cidade (FÜNFGELT, 2004; BIANCHINI et al, 2008).

Os desenhos retilíneos que deram início a marcação, do que posteriormente tornouse o traçado urbano da cidade, resultaram-se das ideias positivistas de seu criador, o Engenheiro Civil Carlos Torres Gonçalves (PEZAT, 2003). Dentre suas características mais expressivas, pode-se afirmar que a avenida central que corta o eixo norte e sul da cidade, é a maior. Essa avenida possui amplas dimensões em largura de suas vias de tráfego veicular, bem como canteiros centrais marcados por vegetação rasteira e espécies arbóreas de médio e grande porte (FÜNFGELT, 2004).

O desenho do traçado urbano do Engenheiro Civil Carlos Torres Gonçalves traz nessa avenida uma praça, ponto de referência da cidade e do próprio traçado. Em seu entorno idealizou-se diretrizes para o centro político, administrativo e religioso, que posteriormente se concretizaram com a implantação dos edifícios da prefeitura e da igreja. A praça em formato circular configura-se como rótula, expressando certa monumentalidade à área central, uma vez que interrompe a linearidade da avenida no eixo norte-sul. Essa praça também é ponto de referência para o cruzamento de outros dois eixos, ou seja, além da avenida central, outras duas vias diagonais ganham força e interligam-se a diferentes faces da cidade (FÜNFGELT, 2004; BIANCHINI et al, 2008).

Os princípios urbanísticos concebidos segundo preceitos técnicos no ano de 1913 apresentam uma similaridade formal com a composição urbana da cidade de Paris, idealizada na época pelo barão Hausmman entre 1853 a 1870¹, e também com a

${ }^{1}$ Paris já era uma cidade consolidada. Haussmann projetou o novo plano, que foi concebido em etapas que perduraram 17 anos (BENEVOLO,1997).
Teoria e práticas urbanas: estética, conhecimento e o traçado urbano da cidade de Erechim/RS. cidade de Belo Horizonte. Essa última desenhada por Aarão Reis em $1897^{2}$. Mas, é com o conhecimento erudito das engenharias que a cidade de Erechim foi pensada.

Diante disso, este artigo tem como objetivo traçar uma análise acerca da estruturação da forma urbana da cidade de Erechim. Sobre dos procedimentos metodológicos utilizados para o desenvolvimento deste artigo, destacam-se: em um primeiro momento foi realizado o levantamento histórico sobre a cidade, conjuntamente foi analisado os processos que proporcionaram a formação da cidade até a implantação do seu traçado, resultando nessa concepção em estudo do traçado urbano de Erechim. O recorte temporal estrutura-se entre o ano de formação da Colônia de Erechim, em 1904, com a demarcação da divisão de terras, seguindo até a entrega do plano por Carlos Torres Gonçalves em 1914. Cabe destacar que posterior à entrega e execução do traçado urbano a cidade continuou a se desenvolver, porém, o que se busca nesse estudo é compreender o traçado urbano proposto à época.

Mesmo com novas delineações resultante da constante evolução e desmembramento de novos loteamentos, o traçado original pode ser observado até os dias atuais, como acontece com as cidades de Paris, Belo Horizonte e Washington, por exemplo. Contextualizando o valor simbólico dos traçados urbanos, Fünfgelt (2004) explica que a memória urbana deve ser preservada como forma de garantir que a identidade da cidade, seja ela cultural ou social, seja construída a partir da essência formada pelas raízes do passado.

Ainda sobre dos procedimentos metodológicos, o presente artigo trata de uma tipologia de pesquisa exploratória, de natureza qualitativa. Para Minayo (2011) esse tipo de estudo com abordagem qualitativa procura abranger os aspectos existenciais do objeto, seus significados e a ocorrência dos fenômenos através da observação dos fatos. No que diz respeito a tipologia exploratória, Gil (2002) explica como um retrato de fatores e particularidades podem caracterizar um dado fenômeno. Para tanto, esse estudo busca compreender as concepções do traçado urbano proposto por Carlos Torres Gonçalves para Erechim, inspirado por outras práticas urbanas da época. Quanto aos dados secundários, esses foram selecionados e sistematizados 
a partir de artigos, dissertações, teses e livros. Sobre as fontes primárias, mapas, relatórios e fotografias foram coletados junto o arquivo Histórico de Erechim.

\section{A constituição formal da Colônia agrícola de Erechim}

A região do Alto Uruguai gaúcho teve início no ano de 1904 com a demarcação de terras para a formação de colônias de imigrantes europeus. Este fato ocorreu concomitante, e influenciado, pela abertura da ferrovia que ligava a cidade de São Paulo/SP a cidade de Rio Grande/RS. Essa ferrovia possibilitava a ligação do sul do Brasil com os demais estados do país (FÜNFGELT, 2004; BIANCHINI et al, 2008).

Conforme avançava os trilhos da ferrovia, também crescia o número de novas estações de trem. Esses locais atraiam a atenção dos imigrantes que residiam próximos a esses pontos de embarque e desembarque, situação que em muito favoreceu para a formação de pequenos povoados. Com o intuito de evitar a invasão de posseiros e ao mesmo tempo dar suporte aos imigrantes, o órgão oficial do governo elaborou a divisão de lotes rurais (FÜNFGELT, 2004; AVER, 2008). O decreto no 313 de 1900 definiu uma área de 25 hectares para cada família, tomando como referência a topografia e cursos d'água existentes (BIANCHINI et al, 2008).

Foi entre a criação das estações e seus parcelamentos de solo rural que nasceu a colônia de Erechim. A planta com data de 1913 caracteriza a divisão de terras (Figura 1). Esse parcelamento agrícola já previa reservas de terras para futuras ocupações urbanas (FÜNFGELT, 2004). No ano de 1908, mais precisamente em 06 de outubro, durante o governo de Calos Barbosa, a Colônia de Erechim foi oficialmente implantada (BIANCHINI et al, 2008).

Com a necessidade de se instalar rapidamente para atender os imigrantes, o engenheiro agrimensor Severiano de Souza Almeida realizou a demarcação das terras rurais e definiu a sede da colônia nas proximidades do $\mathrm{km} 110$ do percurso da ferrovia (BIANCHINI et al, 2008). Este local, onde hoje se localiza o município de Getúlio Vargas, situava-se distante do centro da colônia (Figura 2). Para tanto, a comissão de terras requereu que um novo estudo fosse realizado para redefinição da sede da colônia em uma região mais próxima à estação ferroviária (FÜNFGELT, 2004).
Teoria e práticas urbanas: estética, conhecimento e o traçado urbano da cidade de Erechim/RS.

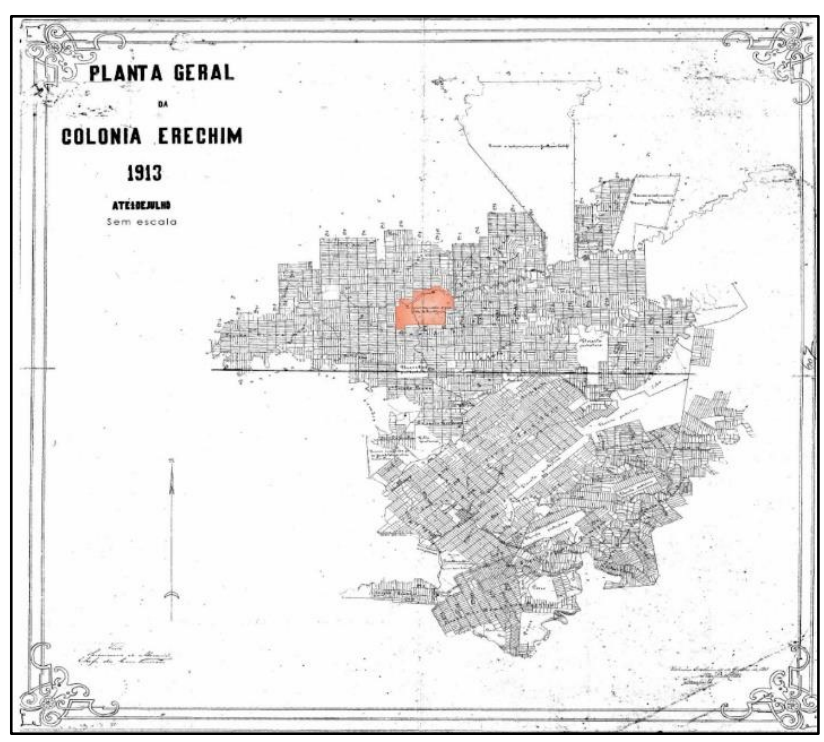

Figura 1: Planta da colônia de Erechim. Na seção denominada de Paiol Grande (em vermelho), destaca-se a área para a formação de uma localidade urbana. Posteriormente, neste local, foi instalada a sede da colônia, a atual cidade de Erechim. Fonte: Arquivo Histórico de Erechim.

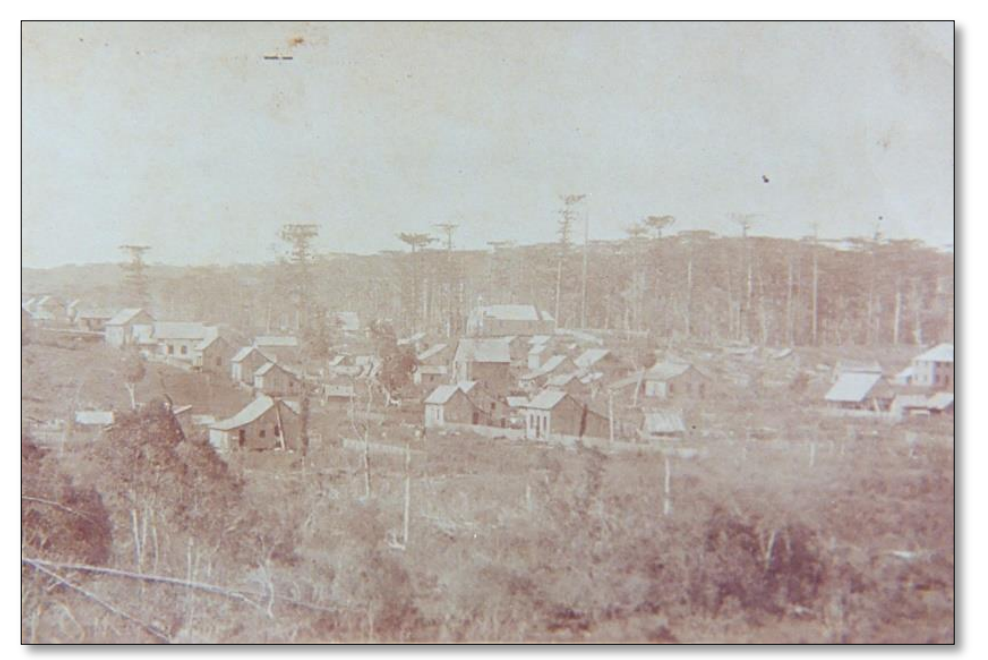

Figura 2: Primeira sede da colônia de Erechim, atual cidade de Getúlio Vargas, no ano de 1912. Fonte: Arquivo Histórico de Erechim. 
Enquanto o estudo acontecia, a então sede da colônia desenvolvia-se paulatinamente. Em 1911 a colônia já atingia o número de 10.000 moradores, muitos deles de diferentes nacionalidades. Sendo que a maioria eram de italianos, alemães e franceses (DUCATTI NETO, 1981). Entre os anos de 1909 e 1911 foram implantadas as estações ferroviárias de Erebango, de Capoerê, de Paiol Grande e de Barro (FÜNFGELT, 2004).

No ano de 1912, frente ao crescente movimento de imigrantes, a colônia de Erechim ganhava cada vez mais destaque no estado, conquanto, a localização inicial da sede, mal planejada, sem estudo prévio e principalmente distante da ferrovia tornava-se um problema recorrentemente destacado pelos moradores local (FÜNFGELT, 2004).

Segundo o Relatório do Governo do Estado:

De todos os povoados da colônia, é atualmente mais importante Erechim, infelizmente mal localizado e mal instalado, sem prévio estudo do terreno, sobretudo em conseqüência do atropelo havido na fase inicial da colônia, devido à entrada de grandes levas de imigrantes (RIO GRANDE DO SUL, 1912, apud AVER,2008, p 64).

Com esse relatório, observa-se a retomada da discussão de readequar a sede da colônia, ou seja, buscar uma nova localização. No ano de 1913, por indicação do governo, decidiu-se por uma área nas proximidades do povoado de Paiol Grande, pois lá havia sido instalada uma estação ferroviária (BIANCHINI et al, 2008).

Além da proximidade com a ferrovia, a nova sede deveria se revestir de outros fatores positivos para sua instalação, como por exemplo: estar "(...) situada na região central, num bello chapadão, o ponto mais alto da vasta região do planalto sulino (...), sendo a estação da serra de maior altitude da rede do estado, com 768 metros" (KARNAL, 1926) (Figura 3).

O traçado da nova sede ficou a cargo da Comissão de Terras, que estava instalada na cidade de Passo Fundo. A área de 2.300 hectares seria $50 \%$ parcelada para lotes urbanos. (FÜNFGELT, 2004). O Engenheiro Carlos Torres Gonçalves, integrante e Chefe da Diretoria da Comissão de terras foi o responsável por elaborar o desenho urbano para a nova sede da colônia.
Teoria e práticas urbanas: estética, conhecimento e o traçado urbano da cidade de Erechim/RS.

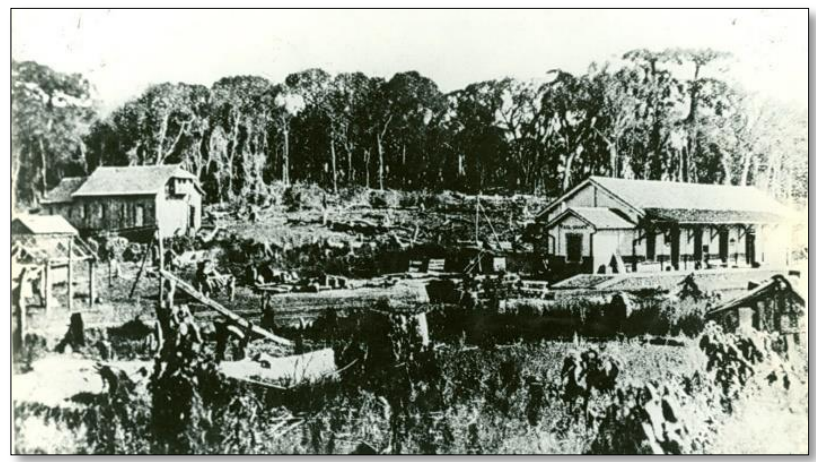

Figura 3: Vista geral do povoado de Paiol Grande, 1912. Fonte: Arquivo Histórico de Erechim.

Durante o período de elaboração do desenho da nova sede, decidiu-se que novas edificações deveriam ser proibidas de serem construídas. $O$ intuito era impedir que tal conjuntura alterasse $o$ andamento do traçado urbano. Mesmo assim, o pequeno povoado de Paiol Grande já dispunha de 41 casas de madeira e 20 estabelecimentos comerciais nesse momento (BIANCHINI et al, 2008).

Todavia, o traçado urbano da nova sede demorou para ser finalizado, sendo que a colônia agrícola continuava em desenvolvimento, alcançando o número de 18.000 mil habitantes em 1913. Com a conclusão da obra de uma ponte entre os estados do Rio Grande do Sul e de Santa Catarina, a vinda de imigrantes de outros estados foi ainda maior (FÜNFGELT, 2004).

A configuração da nova sede gerou algumas reclamações devido ao atraso na entrega do traçado. Isso foi justificado por Torres Gonçalves pela necessidade de revisão do desenho diante das condições topográficas (FÜNFGELT, 2004).

O Relatório de 1914 apresenta as explicações de Torres Gonçalves:

[...] em fins de 1913, e por duas vezes no corrente anno, estive em Paiol-Grande, por motivo da sua installação. Examinado com mais vagar o primitivo projecto no local, o que as minhas funções absorventes não tinham permittido realisar convenientemente nesta cidade, fui levado a introdusir aperfeiçoamentos apreciaveis, tendentes particularmente a embelesal-o, por uma melhor disposição e distribuição das ruas e praças, e tambem a facilitar o transito pelas ruas. Entre os anexos do presente relatório encontra-se o referido projeto, subordinado logicamente as 
condições do terreno, e não simplesmente riscado de maneira arbitrária conforme se costumava fazer. A sede geral da colônia Erechim em Paiol Grande será o primeiro caso deste Estado do estabelecimento de uma cidade com projecto previamente estudado. A sua situação e a sua instalação ordenada a tornarão certamente uma bella cidadesinha futura, cujo nome deve ser trocado por outro menos prosaico escolhido com propriedade (RIO GRANDE DO SUL, 1914, apud AVER, 2008, p. 67).

A nova sede da colônia teve seu traçado idealizado, diferentemente das demais localidades que cresciam de forma espontânea. No ano de 1914 foi implantado o traçado urbano que conforma a área central da cidade de Erechim (BIANCHINI et al, 2008; FÜNFGELT, 2004).

\section{O Engenheiro Civil Carlos Torres Gonçalves}

Carlos Torres Gonçalves nasceu em 1875 na cidade de Rio Grande, região sul do Rio Grande do Sul. Graduou-se em Engenharia Civil na Escola Politécnica do Rio de Janeiro no ano de 1898. Durante sua trajetória de vida teve contato com os ideais positivistas de Augusto Comte. O positivismo tinha sua base resumida no lema "o amor por princípio, a ordem por base e o progresso por fim" (PEZAT, 2003).

Entre 1909 e 1929 atuou no comendo da Diretoria de Terras e Colonização do Rio Grande do Sul (DTC), onde coordenou grande parte da colonização no interior do Estado. Nesse mesmo período o Partido Republicano Rio-Grandense (PRR), conhecido também por sua ideologia positiva, estava no poder.

Inspirados por seus ideais e com o aval do governador à época, Torres Gonçalves idealizou o traçado urbano de Erechim. Erechim foi basicamente traçada como uma malha em formato ortogonal, implantando quatro vias diagonais, tendo como eixo uma praça central, ao qual acreditava ser um símbolo dominante de poder (AVER, 2008).

Segundo Aver (2008), não se encontrou nenhum documento com as explicações sobre o traçado desenvolvido para a nova sede da colônia. A autora afirma que nem mesmo nos relatórios da Comissão de Terras há uma afirmação clara para tal desenho adotado. Todavia, há duas hipóteses para explicar a escolha de tal traçado nos seus projetos: a primeira hipótese configura-se através do seu contato com o curso de engenharia da Escola de Engenharia de Minas, em 1894, bem como 0 curso de engenharia civil da Escola Politécnica do Rio de Janeiro, formando-se
Teoria e práticas urbanas: estética, conhecimento e o traçado urbano da cidade de Erechim/RS. nessa última. $O$ conhecimento adquirido permitiu que o engenheiro pensasse o espaço urbano de forma racional. A outra hipótese indica que Torres Gonçalves projetou Erechim como uma forma de homenagear Paris.

Foi nesta mesma escola politécnica (Rio de Janeiro) que se formaram dois importantes engenheiros que desenvolveram projetos de urbanismo. Um é Aarão Reis que idealizou o projeto urbano para a cidade de Belo Horizonte, seguindo também os ideais positivistas, e Saturnino de Brito, profissional que desenvolveu diversos planos de saneamento no Brasil (FÜNFGELT, 2004).

Conforme relatam Salgado e Piccinato Junior (2011, p. 110), quando analisaram a formação de cidades no nordeste do estado paulista a partir do saber erudito de profissionais das engenharias, a "formações eruditas dos profissionais da engenharia militar e da arquitetura respondem por muitos dos projetos elaborados para as cidades". O conhecimento relacionado à cidade é incorporado nas escolas de engenharias, elas foram responsáveis pela formação de profissionais que contemplaram diferentes áreas do conhecimento, destacando-se: agrimensores, engenheiros agrônomos, engenheiros civis e geógrafos, por exemplo.

Torres Gonçalves entendia que um "projecto" urbano nada mais era do que uma forma de povoar. Entretanto, para isso, era necessário estudar as condições do sítio, compreender o mercado de consumo e, principalmente, realizar um parcelamento de solo coerente (CASSOL, 2003).

No Rio Grande do Sul o ordenamento territorial e urbano foi considerado pelos governantes, e demais representantes, "como um dos mais importantes mecanismos para o controle das cidades e de seus cidadãos [...], objetivando a valorização do solo e os usos adequados ao desenvolvimento do homem na sociedade" (AVER, 2008, p. 63).

\section{Carlos Torres Gonçalves e o traçado urbano de Erechim}

O traçado urbano do engenheiro Carlos Torres Gonçalves para a nova sede da colônia de Erechim iniciou-se a partir de diretrizes legislativas que regulamentavam as colônias do estado nessa época (IOTTI, 2001). Dentre as legislações, destaca-se o decreto $\mathrm{n}^{\circ} 247$ de 19 de agosto de 1899, com destaque para o art. 5ำ que designava uma área dividida em duas zonas idênticas, sendo separadas por uma avenida com 20 metros de largura, e o art. 6º, que deveria ser estabelecido um ponto 
central de referência para a povoação, como por exemplo uma praça, de modo que os lotes urbanos adjacentes teriam preferências para a construção de escolas e edifícios públicos (IOTTI, 2001).

Conforme o decreto que regulamentava a organização das colônias do estado, define-se:

Art $4^{\circ}$ - Em cada núcleo, preferindo-se parte mais central ou a que ficar próxima de rios navegáveis ou de vias férreas e sempre onde haja abundância de água e se verifiquem condições de salubridade, se reservará uma seção de 300 hectares, mais ou menos, para povoação.

Art. $5^{\circ}$ - Essa área será subdividida em duas zonas, iguais e concêntricas, separadas por uma avenida de 20 metros de largura.

$\S 1^{\circ}$ - A área central será dividida em quadras espaçadas umas, de 20 metros, reservando-se duas ou três quadras para praças públicas e subdividindo-se as demais em lotes de $1.250 \mathrm{~m}^{2}$.

$\S 2^{\circ}$ - A outra zona reservar-se-á para logradouros e para o desenvolvimento futuro da povoação, dividindo-se oportunamente em lotes, com prévia autorização do Governo do Estado.

Art. $6^{\circ}$ - Numa praça ou no ponto principal da povoação, serão reservados lotes para escolas (RIO GRANDE DO SUL, 1899, apud AVER, 2008, p. 67).

Seguindo os ideais positivistas, as diretrizes propostas por Torres Gonçalves tomaram como base a racionalidade e a ordem. Conjuntura que se expressa em muitas cidades à época, por exemplo, a Paris de Haussmann (FÜNFGELT, 2004).

O traçado urbano previa uma ocupação para cerca de 15.000 habitantes, dividido em 2.500 lotes urbanos. $O$ traçado ainda apresentava uma área para futura expansão da cidade. Com traçado retilíneo a malha em xadrez resultou em quadras de dimensões homogêneas. Da avenida central, conformada por uma praça denominada na época como Praça Cristóvão Colombo (atual Praça da Bandeira), sobrepõem-se diagonais que cortam o traçado ortogonal da cidade (FÜNFGELT, 2004) (Figura 4).

Essa avenida central é explicada por Aver (2008) com 40 metros de largura, representando o dobro da largura exigida como dimensão mínima no art. 5 do decreto 247. Já nas vias em diagonal a largura corresponde a 25 metros. Mesmo assim, a autora discorre que as vias largas eram um avanço para época, uma vez que o uso do automóvel ainda era restrito a uma pequena parcela da população.
Teoria e práticas urbanas: estética, conhecimento e o traçado urbano da cidade de Erechim/RS.

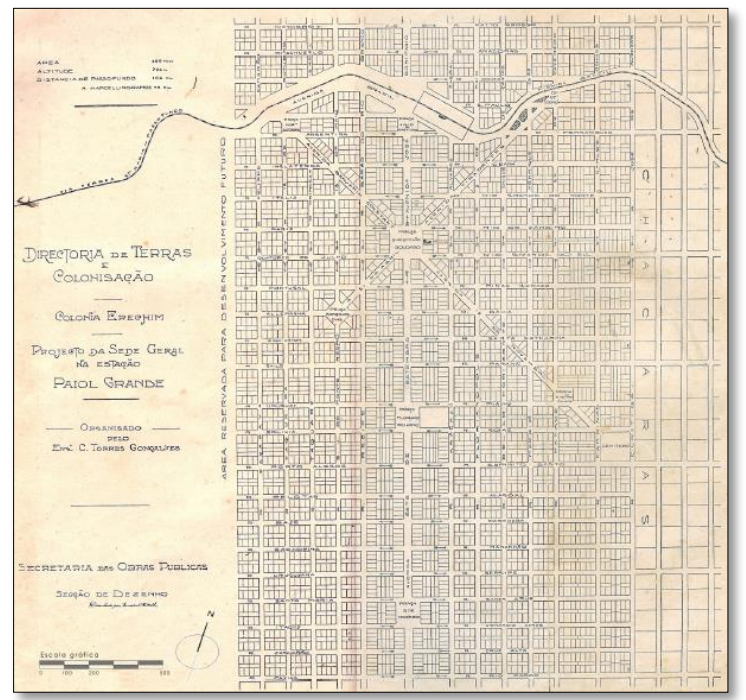

Figura 4: Mapa da proposta de Carlos Torres Gonçalves para a nova sede da Colônia de Erechim, na Estação de Paiol Grande. Fonte: Arquivo Histórico de Erechim.

Aver (2008, p.67) ainda expõe que "as vias de dimensões generosas estavam em voga na época, pois, mais do que embelezar, aumentavam as condições de segurança nas cidades, frequentemente assoladas por invasões e revoltas".

Ainda sobre o traçado urbano de Torres Gonçalves, na direção leste as chácaras de maiores dimensões apresentavam conformações ortogonais, o intuito era manter o traçado retilíneo na área de expansão. As chácaras poderiam ser fracionadas no futuro, atendendo uma demanda por mais lotes. Para o lado oeste, a descrição "área para desenvolvimento futuro" revela a visão de futuro, isto é, de crescimento que poderia vir a ocorrer. Conquanto, não há um desenho do parcelamento dessa área (FÜNFGELT, 2004).

Nas faces da praça previu-se a instalação do centro político, administrativo e religioso, concretizando-se com a construção da prefeitura, da catedral, do fórum e do edifício da "Comissão de Terras" (FÜNFGELT, 2004) (Figura 5). Esse último, até hoje é um marco histórico patrimonial na cidade, chamado popularmente de "Castelinho". 


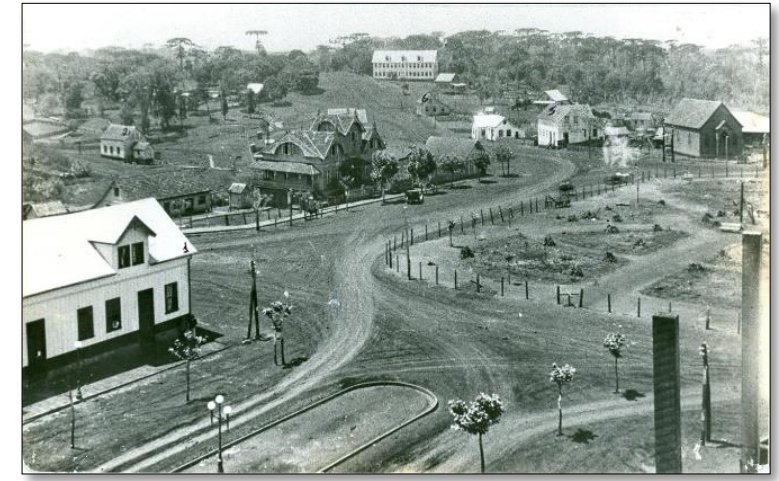

Figura 5: Erechim na década de 20. No centro observa-se o prédio em madeira da Comissão de Terras. A direita a Praça da Bandeira, anteriormente denominada como Praça Cristóvão Colombo. Fonte: Arquivo Histórico de Erechim.

O traçado urbano foi ancorado na ideia de vias como função principal de circulação na cidade. A avenida principal, no sentido norte/sul, foi dividida ainda com mais uma praça, denominada Praça Jaime Lago. Todos os eixos receberam a nomenclatura de avenidas, demonstrando que essas vias teriam maior importância e domínio sobre as demais ruas (FÜNFGELT, 2004).

Estava prevista a construção de oito praças, em consonância com os eixos centrais, cada uma dela criando perspectivas a partir de pontos de fuga. Quanto aos lotes urbanos, a dimensão era de $1.250 \mathrm{~m}^{2}$, ou seja, a área mínima determinada pelo Governo. A ferrovia não interferiu no traçado, houve uma readequação do desenho em relação ao percurso dos trilhos do trem, mesmo assim, seguindo com o mesmo traçado depois de ultrapassar os limites do trajeto do trem. Nas quadras adjacentes a ferrovia, houve adaptações às curvas dos trilhos, além de traçar uma avenida circunscrevendo toda extensão ferroviária dentro do limite urbano (FÜNFGELT, 2004).

O traçado urbano foi concebido a partir de princípios da horizontalidade e permaneceu desta forma até a década de 50 (Figura 6). Erechim cresceu rapidamente depois deste período, mais precisamente entre 1960 e 1980 onde a verticalização ganhou destaque no ambiente urbano (Figura 7). Nesse momento as intenções eram apresentar uma cidade desenvolvida e baseada no que os grandes centros estavam idealizando naquela época (CHIAPARINI, SMANIOTTO, FÁBRIS E HACHMANN, 2012).

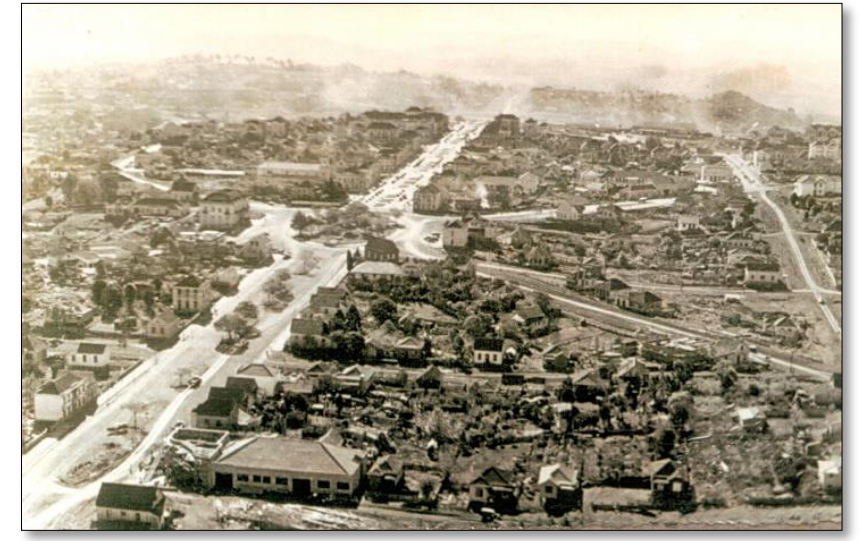

Figura 6: Vista aérea de Erechim, 05 de dezembro de 1947. Fonte: Arquivo Histórico de Erechim.

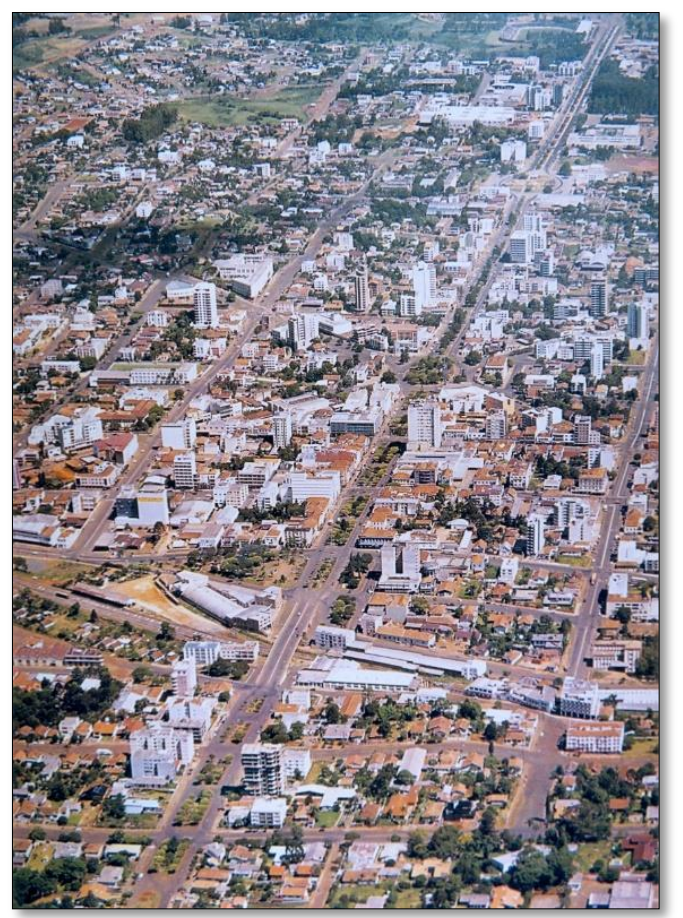

Figura 7: Vista aérea de Erechim, 1993. Nesta imagem nota-se a verticalização da cidade. Fonte: Arquivo Histórico de Erechim. 


\section{Resultados e discussões}

Conforme já mencionado anteriormente, Torres Gonçalves não só acreditava na filosofia positivista, como vivenciou as diretrizes dessa corrente do pensamento de forma singular nas suas ações, tanto pública, como na sua vida privada (PEZAT, 2003). Os reflexos podem ser percebidos no traçado urbano da colônia de Erechim. Os eixos são bem definidos, ou seja, as vias são claramente os elementos mais fortes e influenciadores no traçado, tornando-se o ponto de partido do desenho urbano. As linhas retilíneas formando quadrículas são replicadas em ambos os lados do eixo principal (Figura 8).

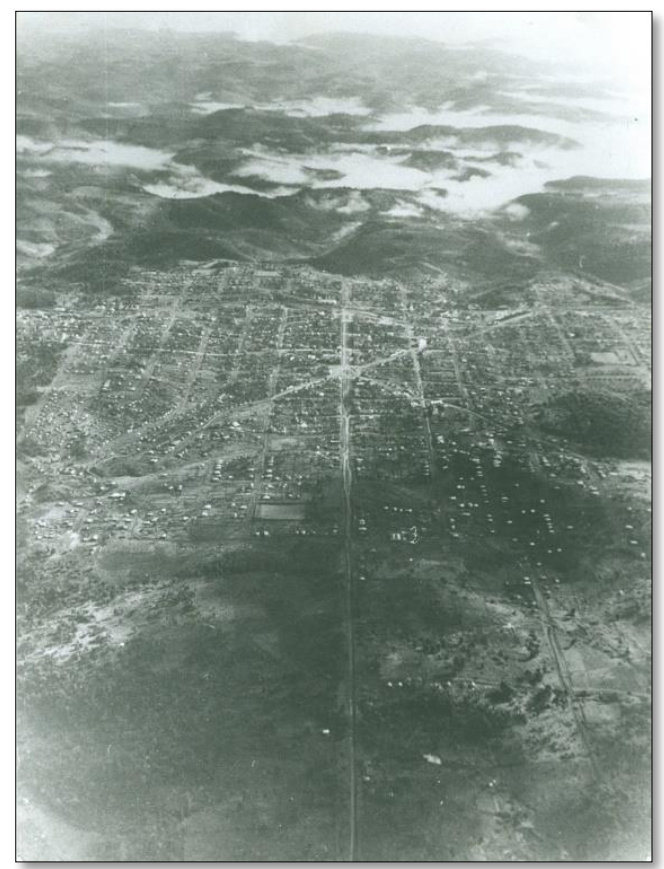

Figura 8: Vista aérea da cidade de Erechim, 1947. Fonte: Arquivo histórico de Erechim.

É interessante notar, no que se refere à justificativa elaborada por Torres Gonçalves perante o atraso na entrega do projeto, que estava-se sendo realizadas adaptações no "projecto" urbanístico para uma melhor adequação da situação topográfica do
Teoria e práticas urbanas: estética, conhecimento e o traçado urbano da cidade de Erechim/RS.

terreno. Contudo, essa justificava não se sustenta, uma vez que ele estabeleceu a malha ortogonal sobre o território físico como traçado, sem considerar as curvas de nível. Tal rigidez ocasiona até hoje quadras com grandes desníveis, algumas com condições difíceis de acessibilidade (FÜNFGELT, 2004).

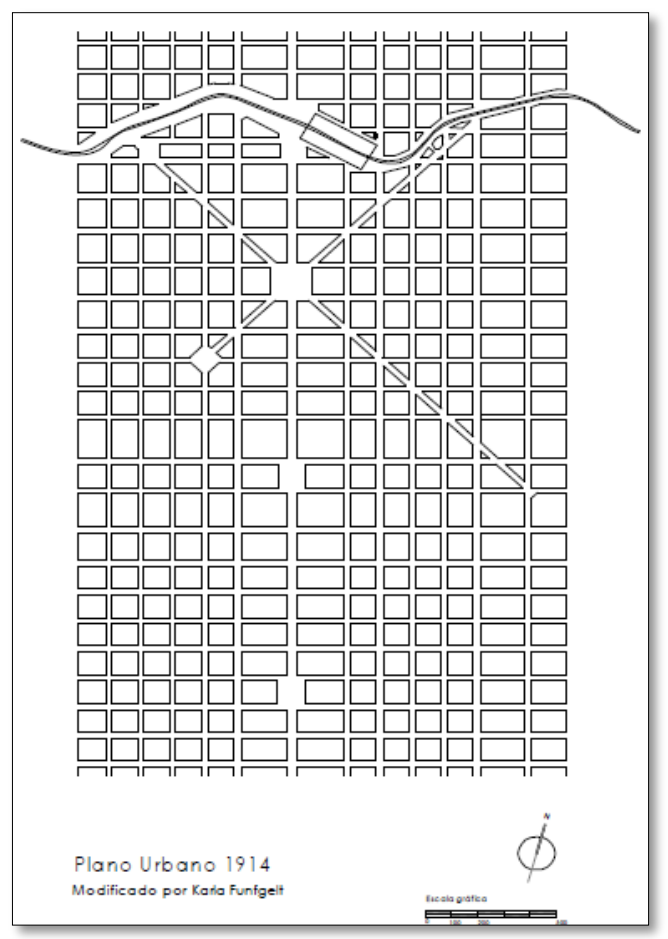

Figura 9: Desenho realizado por Fünfgelt (2004) com base no plano original de Carlos Torres Gonçalves, indicando a forte hierarquia dos eixos e do traçado retilíneo. Nas adjacências da linha férrea nota-se a mudança do traçado, adequando-se ao sítio. Fonte: Fünfgelt, 2004.

Por outro lado, pode ser que as adequações em função do sítio, como descreveu Torres Gonçalves, referiam-se apenas as adequações as margens da ferrovia, esta que, por sua vez foi limitante ao traçado que ele estava idealizando. É possível ponderar que as quadras adjacentes ao percurso da ferrovia foram adaptadas, adquirindo formatos diferentes a malha em xadrez. Mesmo assim, as quadras subsequentes retomam os princípios de regularidade e forma (Figura 9). 
Para Bardet (1990), este princípio de regularidade permite um rápido deslocamento, típico da cidade clássica. $O$ autor destaca ainda que tal traçado se inspira na dinâmica dos fluxos, isto é, toma-se como parâmetro diferentes perspectivas, ao mesmo tempo em que se permite uma fruição do movimento.

Quando se examina os traçados urbanos de Erechim e Paris, é possível destacar alguns aspectos interessantes. Inicialmente, tanto Paris, como Erechim, possuem os eixos definidores, marcando a paisagem e criando um ponto focal. No caso de Paris, o ponto focal é o Arco do Triunfo. Já em Erechim o ponto é a Praça da Bandeira. Nela encontra-se um elemento importante para a cidade, o chafariz. Quanto à Praça, Aver (2008) ressalta a dimensão expressiva dela, circunvizinha da igreja, do poder executivo, do poder legislativo e do poder judiciário. A presença desses poderes próximos uns dos outros revelam um traço da filosofia positivista, tomando como ideia para o ordenamento urbano a concentração de poderes na configuração da cidade.

Outro aspecto interessante, e neste caso distinto entre os traçados de Erechim e Paris, refere-se ao o formato das quadras nas adjacências dos eixos. Nota-se em Erechim a rigidez de linhas retas originando quadras em formato retangulares e/ou quadradas que se diferem apenas nos tamanhos. Ainda em Erechim, com a sobreposição dos eixos na diagonal, algumas quadras foram fracionadas em duas, ou seja, cortadas em sua maior direção resultando em dois triângulos que ainda assim permanecem com a configuração de linhas retas. Conforme já descrito anteriormente, a configuração na malha urbana de Erechim, as únicas quadras que sofreram mais adaptações foram quadras próximas à linha férrea (Figura 10).

Esse discurso acerca da inspiração da forma urbana de Paris inspirando o traçado urbano de Erechim necessita de mais dados analíticos. Porém, o que se pode contextualizar com maior coerência é que o traçado de Erechim reflete um outro momento da história nacional, ou seja, com o advento da República, intensifica-se um esforço construtivo destinado à produção de um território organizado dentro dos preceitos "modernos", dos referenciais socioeconômicos e culturais.

Para Gitahy (2005), quando analisou o desenho das cidades paulistas na primeira metade do século $X X$, revela que construir infraestrutura moderna, requalificando as relações entre cidade e campo e os espaços produtivos no interior deles, bem como o lugar do próprio Brasil na divisão internacional do trabalho, não era apenas
Teoria e práticas urbanas: estética, conhecimento e o traçado urbano da cidade de Erechim/RS. uma tarefa de construção física, mas também de instituições sociais voltadas para uma formação intelectual e para a redefinição das próprias relações sociais.

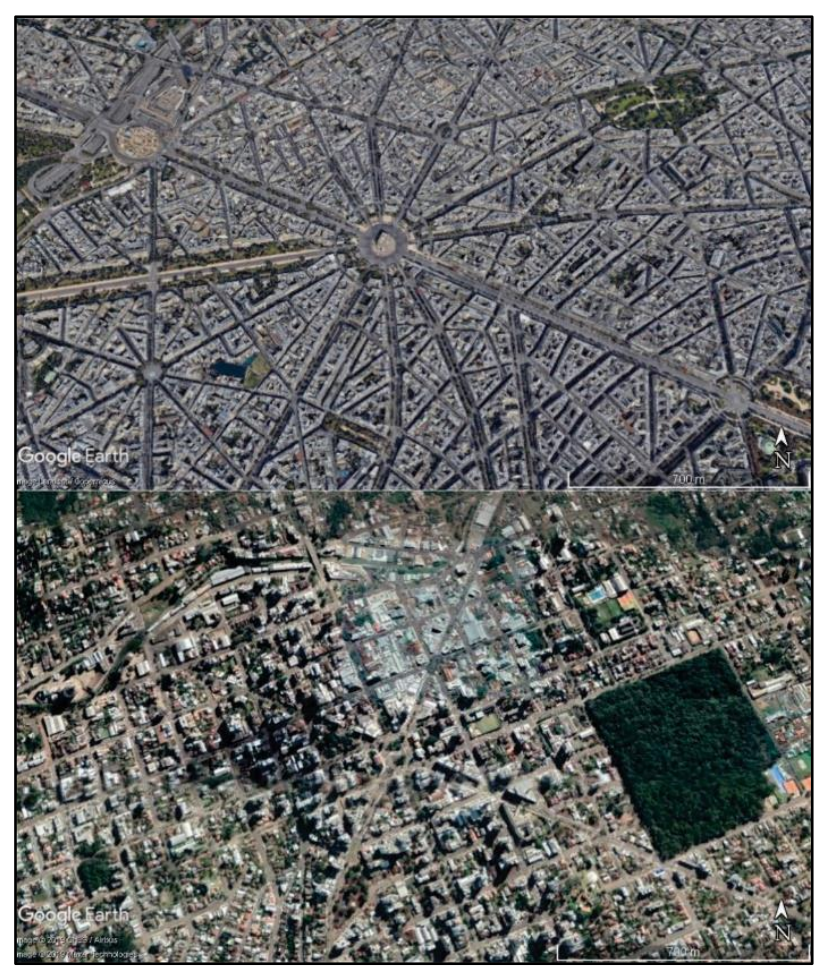

Figura 10: Imagem comparativa entre Paris e Erechim. A primeira Paris, ao centro identifica-se o Arco do Triunfo. A imagem abaixo, também uma vista aérea, refere-se a cidade de Erechim, com a centralidade na Praça da Bandeia. Na parte superior da imagem de Erechim nota-se em uma linha organica, o antigo percurso dos trilhos do trem e a estação, ambos desativados. Fonte: Google Earth, adaptado pelos autores, 2019.

Essa conformação em São Paulo, já vinha sendo estruturada anteriormente principalmente nas últimas décadas do século XIX, pelo Engenheiro Civil Antonio Francisco de Paula Souza, que se destacou por projetar além de ferrovias, as redes de abastecimento de água e esgoto para muitas cidades paulistas. Suas propostas já lançavam preceitos que viriam a ser consolidados nos anos seguintes com um moderno planejamento territorial (CAMPOS, 2007). 
Para Simões Júnior (2013), as primeiras décadas do século XX representou o estabelecimento de um novo padrão de ocupação do território e de construção de edificações, objetivando o enfrentamento de problemas sanitários e das epidemias, em razão da concentração humana. Nesse sentido, muitas cidades, com os planos de saneamento foram reestruturadas, em contrapartida, outras cidades já nasciam a partir da implantação de redes de infraestrutura sanitária, de iluminação e de transporte. Integravam ainda a essa conjuntura, a realização de projetos de embelezamento urbano, de criação de espaços de cunho cívico e monumental, assim como de áreas verdes e espaços públicos de lazer. A gestão da cidade também passava por aperfeiçoamentos, uma vez que a consolidação do poder político na dimensão da esfera municipal permitiu a criação de novos cargos administrativos que foram sendo ocupados por profissionais com formação técnica.

A influência de modelos e práticas urbanísticas advindas do cenário internacional estava fortemente marcada pelo poder exercido pela cultura francesa sobre nossas elites e governantes, particularmente $o$ ideário positivista. A referência urbanística que imprimia um novo posicionamento em relação as cidades era o plano que o prefeito Haussmann tinha executado para a cidade de Paris na década de 1850, destruindo a malha urbana e viária medieval da área central, propondo largas avenidas e implantando sistemas modernos de infraestrutura, parques, edifícios públicos, além de uma padronização estética para as novas construções. Pereira Passos, no projeto de modernização da cidade do Rio de Janeiro, adotou as premissas haussmannianas, pois vivera em Paris na época das transformação da cidade francesas. Outras capitais como Salvador, Recife, Fortaleza e Porto Alegre seguiram caminhos similares aos do Rio de Janeiro, procurando adequar suas antigas estruturas coloniais às premissas da modernidade. No campo da engenharia, a contribuição à cidade aconteceria através de planos integrados de saneamento envolvendo drenagem, canalização de cursos d'água, tratamentos de esgotos e abastecimento de água potável (SIMÕES JÚNIOR, 2013).Segundo Bertoni (2010), esse período da história do urbanismo é caracterizado por uma multiplicidade de saberes e de disciplinas que ambicionaram a hegemonia sobre as questões sociais urbanas. A contribuição dos técnicos para a construção da cidade como objeto de conhecimento, de reforma e de ação coloca a questão da mudança da escala de intervenção de cada profissional junto a realidade das cidades.
Teoria e práticas urbanas: estética, conhecimento e o traçado urbano da cidade de Erechim/RS.

O traçado urbano da cidade de Erechim insere-se nesse contexto, isto é, o de desenhar uma cidade tendo como referência o conhecimento, o saber erudito das engenharias que possibilitou não só a reestruturação das cidades existentes, assim como na formação de novas cidades segundo os preceitos modernizadores e racionais desses saberes.

\section{Considerações finais}

Diante do contexto descrito sobre a história de Erechim, Torres Gonçalves deixou um legado importante, não só para a cidade de Erechim, bem como para o Rio Grande do Sul. Sua significativa participação à frente de cargos públicos do estado, coordenando e atuando tiveram um papel de destaque na configuração do território, principalmente na assídua e constante urbanização das terras ainda devolutas. Torres propôs e construiu estradas, pontes e elaborou planos urbanos de colonização, entre outras obras públicas (PEZAT, 2003).

A compreensão do processo histórico da construção das primeiras ideias da cidade de Erechim face a suas transformações urbanas são características marcantes e retomam o assunto da preservação diante dos fatos históricos que devem ser considerados. A memória urbana faz parte da cidade de Erechim, oriunda de diferentes camadas, por vezes se sobrepondo conforme a época, mas ao final, buscando compreender a sua gênese. A avenida principal, com demasiada largura para época, onde veículos automotores eram quase que inexistentes, não apresentou justificativa para sua construção. A razão da expressiva dimensão foi dada em nome da inovação. Nos dias de hoje, a mesma avenida apresenta-se menor, dado tamanho crescimento que a cidade se encontra, e consequentemente o aumento de veículos em circulação.

Mesmo que não haja dados comprovatórios que sustentem a ideia de concepção formal de Erechim inspirada em Paris, conquanto, é possível perceber algumas semelhanças interessantes entre o traçado urbano de ambas. Nos dois traçados o fato dos eixos serem indutores do plano urbano, delineados pelas vias que priorizam a circulação, mostram-se dotados de uma dimensão que permite a visualização marcante e necessária para sua compreensão. Tal conjuntura, conforme aponta Simões Júnior (2013), revela que a abertura de grandes avenidas assume um caráter emblemática, de modo a haussmannização tornou-se uma panaceia, ou seja, uma solução a ser contextualizada quando o assunto era a cidade. 
Assim, o presente artigo nos permiti concluir que o traçado urbano da cidade de Erechim integra e representa, numa escala de estudo local, esse momento da construção do corpus disciplinar urbanismo, onde os diferentes profissionais e seus respectivos saberes eruditos configuraram e reconfiguraram as diferentes realidades urbana brasileiras.

Um outro aspecto que essa análise nos permite conjecturar, mas que precisa ser mais bem explorado, é a ideia de que o planejamento territorial, realizado pela Comissão de Terras no estado do Rio Grande do Sul, precedeu o projeto urbano. O problema não estava em desenhar, desenvolver o traçado urbano, mas em planejar o Estado em seu território. Para tanto, a forma urbana seria uma consequência, ou seja, ela estaria muito mais relacionada ao papel que poderia desempenhar na articulação desse território que estava sendo desenhado pelos engenheiros, e a imigração europeia foi mais peça nesse planejamento territorial.

\section{Referências}

AVER, Ivana Karine. Erechim, processo e projeto: relações estruturais entre traçado viário e desenvolvimento urbano. 2008. Dissertação (Mestrado em planejamento urbano e regional). Universidade Federal do Rio Grande do Sul, Porto Alegre, 2008.

BENEVOLO, Leonardo. História da cidade. São Paulo: Perspectiva, 1991.

BENINCÁ, Dirceu. Severiano de Almeida e sua história. Passo Fundo: Berthier, 1990.

BERTONI, Angelo. A trajetória profissional no estudo da circulação de saberes sobre a cidade. In: SALGADO, Ivone; BERTONI, Angelo (orgs.). Da construção do território ao planejamento das cidades: competências técnicas e saberes profissionais na Europa e nas Américas (1850-1930). São Carlos: RiMA Editora, 2010.

BIANCHINI, Greisi Mara et al. Erechim: A trajetória de Formação Urbana do Município. In: $1^{\circ}$ Congresso Internacional de Tecnologias para o Maio Ambiente, 2008. Bento Gonçalves. Anais... Bento Gonçalves, 2008

CAMPOS, Cristina de. Ferrovias e saneamento em São Paulo: o engenheiro Antonio de Paula Souza da rede de infra-estrutura territorial urbana paulista, 18701893. 2007. 411 f. Tese (Doutorado) - Curso de Arquitetura e Urbanismo, Universidade de São Paulo, São Paulo, 2007.
Teoria e práticas urbanas: estética, conhecimento e o traçado urbano da cidade de Erechim/RS. CHIAPARINI, Enori José; SMANIOTTO, Maria Lúcia Carrarro; FÁBRIS, Neivo Ângelo; HACHMANN, Roberto. Erechim: Retratos do Passado, Memórias do Presente. Erechim: Graffoluz, 2012.

DUCATTI NETO, Antonio. O Grande Erechim e sua História. Porto Alegre: Grafosul, 1981.

FÜNFGELT, Karla. História da paisagem e evolução urbana da cidade de Erechim - RS. 2004. Dissertação (Mestrado em Geografia). Universidade Federal de Santa Catarina, Florianópolis, 2004.

GIL, Antônio Carlos. Como elaborar projetos de pesquisa. São Paulo Atlas, 2002

GITAHY, Maria Lucia Caira. Estudos de História e Fundamentos Sociais da Arquitetura e do Urbanismo em São Paulo. In: GITAHY, Maria Lucia Caira (org.). Desenhando a cidade do século XX. São carlos: RiMA, 2005.

IBGE, Cidades. Disponível em: https://cidades.ibge.gov.br/. Acesso em: 15 de out. 2019

IOTTI, Luiza Horn (org). Imigração e Colonização Legislação de 1747 - 1915. Porto Alegre: EDUCS, 2001.

JEUDY, Henri-Pierre. Memórias do Social. Rio de Janeiro: Forense Universitária, 1990.

KARNAL, Oscar da Costa. Subsídios para a história do município de Erechim. Porto Alegre: Livraria do Globo, 1926.

LEFEBVRE, Henri. A revolução Urbana. Belo Horizonte: UFMG, 2002.

LEFEBVRE, Henri. O direito à cidade. São Paulo: Centauro, 2001.

MINAYO, Maria Cecília de Souza. Pesquisa social: Teoria, método e criatividade. 31 ed. Petrópolis: Vozes, 2011.

PEZAT, Paulo Ricardo. Carlos Torres Gonçalves, a família, a pátria e a humanidade: a recepção do positivismo por um filho espiritual de Auguste Comte e de Clotilde de Vaux no Brasil (1875-1974). 2003. Tese (doutorado em História). Universidade Federal do Rio Grande do Sul, Porto Alegre, 2003. 
SALGADO, Ivone; PICCINATO JUNIOR, Dirceu. O saber técnico de profissionais das engenharias na conformação do urbano no nordeste do estado de São Paulo. Estudos de caso Cristais Paulista e Orlândia. Cadernos de Pós-graduação em Arquitetura e Urbanismo. São Paulo: Mackenzie, 2011.

SANTOS, Milton. Espaço e Método. São Paulo: Nobel, 1997.

SIMÕES JÚNIOR, José Geraldo. O ideário dos engenheiros e os planos realizados para as capitais brasileiras ao longo da Primeira República. In: CAMPOS, Cristina de; ANTIQUE, Fernando; DANTAS, George A. F. Profissionais, práticas e representações da construção da cidade e do território. São Paulo: Alameda, 2013. 